\title{
Triterpenoid saponins from the aerial parts of Trifolium argutum Sol. and their phytotoxic evaluation
}

\author{
Andy J. Pérez ${ }^{\mathrm{a}, *}$, Ana M. Simonet ${ }^{\mathrm{b}}$, Łukasz Pecio ${ }^{\mathrm{a}}$, Mariusz Kowalczyk ${ }^{\mathrm{a}}$, Juan M. Calle ${ }^{\mathrm{b}}$, \\ Francisco A. Macías ${ }^{\mathrm{b}}$, Wiesław Oleszek ${ }^{\mathrm{a}}$, Anna Stochmal ${ }^{\mathrm{a}}$ \\ a Department of Biochemistry and Crop Quality, Institute of Soil Science and Plant Cultivation, State Research Institute, ul. Czartoryskich 8, 24-100 Puławy, \\ Poland \\ ${ }^{\mathrm{b}}$ Grupo de Alelopatía, Departamento de Química Orgánica, Instituto de Biomoléculas (INBIO), Facultad de Ciencias, Universidad de Cádiz, C/República \\ Saharaui s/n, Apdo. 40, 11510-Puerto Real (Cádiz), Spain
}

\section{A R T I C L E I N F O}

\section{Article history:}

Received 27 March 2015

Received in revised form 13 May 2015

Accepted 20 May 2015

Available online 16 June 2015

\section{Keywords:}

Trifolium argutum Sol.

Triterpenoid saponins

Structural elucidation

Phytotoxic activity

Structure-activity relationship

\begin{abstract}
A B S T R A C T
Four triterpenoid saponins (1-4) were isolated from the aerial parts of Trifolium argutum Sol. (sharptooth clover) and their structures were elucidated by comprehensive spectroscopic analysis, including $1 \mathrm{D}$ and 2D NMR techniques, mass spectrometry and chemical methods. Two of them are new compounds, characterized as 3-O-[ $\alpha$-L-rhamnopyranosyl- $(1 \rightarrow 2)-\beta$-D-galactopyranosyl-( $1 \rightarrow 2)-\beta$-D-glucuronopyranosyl]-3 $\beta, 24$-dihydroxyolean-12-ene-22-oxo-29-oic acid (1) and 3-O-[ $\beta$-D-galactopyranosyl-( $1 \rightarrow 2)$ $\beta$-D-glucuronopyranosyl]-3 $\beta, 24$-dihydroxyolean-12-ene-22-oxo-29-oic acid (2). The occurrence of $3 \beta, 24$-dihydroxyolean-12-ene-22-oxo-29-oic acid (melilotigenin) in its natural form is reported for the first time as a triterpenoid aglycone within Trifolium species. The phytotoxicity of compounds was evaluated on four STS at concentration $1 \mu \mathrm{M}$ to $333 \mu \mathrm{M}$. Compound 1 was the most active, showing more than $60 \%$ inhibition on the root growth of $L$. sativa at the higher dose, with $\mathrm{IC}_{50}(254.1 \mu \mathrm{M})$ lower than that of Logran $^{\circledR}(492.6 \mu \mathrm{M})$, a commercial herbicide used as positive control. The structure-activity relationships indicated that both aglycones and glycosidic parts may influence the phytotoxicity of saponins.
\end{abstract}

(c)2015 Phytochemical Society of Europe. Published by Elsevier B.V. All rights reserved.

\section{Introduction}

Clover genus (Trifolium L.) is one of the largest genera in the family of Leguminosae (Fabaceae) with approximately 250 species. They are widely grown as livestock forage and green manure crops and at least 16 species are actively cultivated (Ellison et al., 2006). One of them is sharp-tooth clover, Trifolium argutum Sol. an annual herb plant distributed in Europe, Middle East, Australia and Egypt (Bisby et al., 1994), from which scarce phytochemical information is available in the literature. The occurrence of triterpenoid saponins among Trifolium species have extensively been documented (Jurzysta et al., 1989; Sakamoto et al., 1992; Mohamed et al., 1995; Simonet et al., 1999; Oleszek and Stochmal, 2002; Pawelec et al., 2013; Pérez et al., 2013b). Saponins in these plants are a mixture of triterpenoid pentacyclic glycosides which are often derivatives of soyasapogenol A, B, C and E., having hydroxymethyl group at C-24 and double bond between C-12 and $\mathrm{C}-13$ as a common feature. The sugar portion consists of one or

\footnotetext{
* Corresponding author. Tel.: +48 8188 63421x206; fax: +48 8188 63421x295. E-mail address: aperez@iung.pulawy.pl (A.J. Pérez).
}

three units, where $\beta$-D-glucuronic acid is linked at C-3 position of the aglycone moiety. Despite the wide range of pharmacological properties attributed to triterpenoid saponins, they have also been described for their detrimental effects over the plant growth when releasing into the soil (Marchaim et al., 1974; Oleszek et al., 1992; Oleszek, 1993). Triterpenoid saponins have recently been investigated for their phytotoxic activity (Hernández et al., 2011; Scognamiglio et al., 2012). This paper reports the isolation and structure elucidation of two new triterpenoid saponins $(\mathbf{1}, \mathbf{2})$, along with two known analogs $(3,4)$ from $T$. argutum Sol. aerial parts, and their phytotoxic evaluation against the germination and development of four standard target species (STS).

\section{Results and discussion}

\subsection{Characterization of the compounds}

Dried aerial parts of $T$. argutum were extracted exhaustively with $70 \% \mathrm{EtOH}$. The hydroalcoholic extract was partitioned in $n$ $\mathrm{BuOH} / \mathrm{H}_{2} \mathrm{O}$ and the organic phase was subjected to chromatographic fractionation using reverse-phase RP-18 on a gradient 
of $\mathrm{Me}_{2} \mathrm{CO} / \mathrm{H}_{2} \mathrm{O}$ and other multiple separation procedures to give two new triterpenoid saponins ( $\mathbf{1}$ and $\mathbf{2}$ ) and two known analogs: 3-O- $\beta$-D-glucuronopyranosyl melilotigenin (caraganin B) (3) (Zheng et al., 2013), 3-O-[ $\alpha$-L-rhamnopyranosyl- $(1 \rightarrow 2)-\beta$-D-galactopyranosyl-( $1 \rightarrow 2)-\beta$-D-glucuronopyranosyl] soyasapogenol B (soyasaponin-I) (4) (Kitagawa et al., 1988) (Fig. 1). The structures of the compounds were elucidated on the basis of spectroscopic data obtained from ${ }^{1} \mathrm{H},{ }^{13} \mathrm{C}, 2 \mathrm{D}$ (HSQC, HMBC, DQF-COSY, TOCSY, ROESY, HSQC-TOCSY), 1D-ROESY (250 ms) and 1D-TOCSY (30, 60, $120 \mathrm{~ms})$ NMR experiments, HRESI-TOFMS, ESI-MS/MS and acid hydrolysis.

Compound 1 was obtained as a white amorphous powder and its molecular formula was assigned as $\mathrm{C}_{48} \mathrm{H}_{74} \mathrm{O}_{20}$ based on data from HRESI-TOFMS ( $m / z 969.4696[\mathrm{M}-\mathrm{H}]^{-}$, calcd. for $\mathrm{C}_{48} \mathrm{H}_{73} \mathrm{O}_{20}$, 969.4695). In the negative ESI-MS/MS spectrum, the deprotonated molecule $[\mathrm{M}-\mathrm{H}]^{-}$at $m / z 969$ suffered the successive neutral losses of $\mathrm{H}_{2} \mathrm{O}\left(18 \mathrm{Da}\right.$ ) and $\mathrm{CO}_{2}$ (44 Da) to produce the $\mathrm{m} / z 951$ and 907 ions, respectively, indicating the presence of a carboxylic group. Further fragment ions at $m / z 761$ and 599 indicated the neutral losses of a deoxyhexose unit (146 Da) and a hexose unit (162 Da), respectively. The successive neutral loss of 114 Da to generate the ion at $m / z 485$, suggested the presence of a hexuronic acid unit. It is originated from the ion at $m / z 599$, corresponding to a molecular rearrangement derived from hexuronic acid after losses of water and carbon dioxide (Gülcemal et al., 2013). The ${ }^{1}$ H NMR spectrum of 1 showed for the aglycone moiety signals of six tertiary methyl groups at $\delta$ $0.90,0.98,0.99,1.13,1.26$ and 1.26 (Table 1) and these were correlated in the HSQC spectrum with carbons at $\delta 16.3,17.3,21.0$,

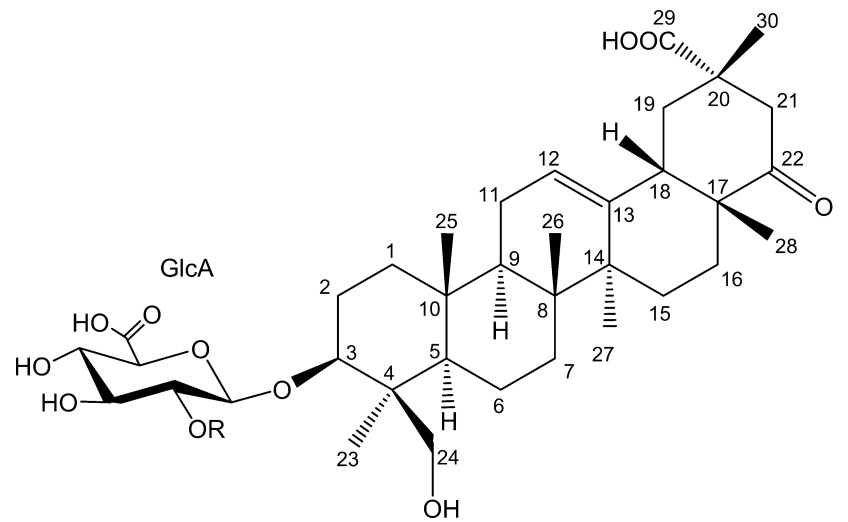

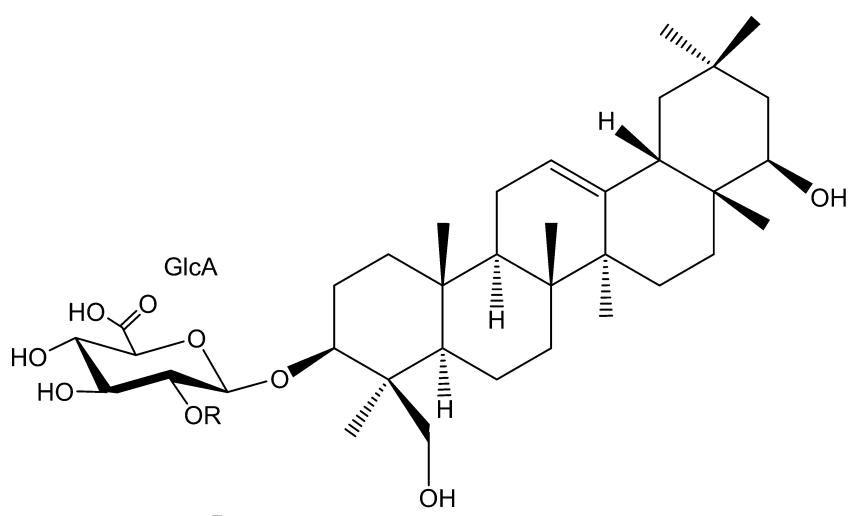

$\mathrm{R}$

$4 \mathrm{Rha}(1 \longrightarrow 2) \mathrm{Gal}$

Fig. 1. Structures of saponins (1-4) isolated from T. argutum aerial parts.
Table 1

${ }^{13} \mathrm{C}$ and ${ }^{1} \mathrm{H}$ NMR data for the aglycone moiety of compounds $\mathbf{1}$ and $\mathbf{2}(500 \mathrm{MHz}) .{ }^{\mathrm{a}}$

\begin{tabular}{|c|c|c|c|c|}
\hline & \multicolumn{2}{|l|}{$\mathbf{1}^{\mathrm{b}}$} & \multicolumn{2}{|l|}{$\mathbf{2}^{\mathrm{c}}$} \\
\hline & $\delta_{\mathrm{C}}$, type & $\delta_{\mathrm{H}}(\mathrm{J}$ in $\mathrm{Hz})$ & $\delta_{\mathrm{C}}$ & $\delta_{\mathrm{H}}(J$ in $\mathrm{Hz})$ \\
\hline $1_{\mathrm{ax}}$ & \multirow[t]{2}{*}{$39.6, \mathrm{CH}_{2}$} & $1.05^{\mathrm{d}}$ & \multirow[t]{2}{*}{39.6} & $1.03^{\mathrm{d}}$ \\
\hline $1_{\text {eq }}$ & & $1.65^{\mathrm{d}}$ & & $1.65^{d}$ \\
\hline $2 \mathrm{ax}$ & \multirow[t]{2}{*}{ 27.1, $\mathrm{CH}_{2}$} & 1.83 ddd $(13.7,11.6,3.6)$ & \multirow[t]{2}{*}{27.1} & $1.83^{\mathrm{d}}$ \\
\hline $2_{\mathrm{eq}}$ & & $2.08^{\mathrm{d}}$ & & $2.00^{\mathrm{d}}$ \\
\hline 3 & $92.4, \mathrm{CH}$ & $3.42 \mathrm{dd}(11.6,4.5)$ & 92.2 & 3.40 dd $(11.5,4.8)$ \\
\hline 4 & 44.7, C & - & 44.6 & - \\
\hline 5 & $57.2, \mathrm{CH}$ & $0.96^{\mathrm{d}}$ & 57.2 & $0.97^{d}$ \\
\hline $6_{\mathrm{ax}}$ & \multirow[t]{2}{*}{$19.3, \mathrm{CH}_{2}$} & $1.37^{\mathrm{d}}$ & \multirow[t]{2}{*}{19.4} & $1.40^{\mathrm{d}}$ \\
\hline 6 eq & & $1.65^{\mathrm{d}}$ & & $1.65^{\mathrm{d}}$ \\
\hline $7 \mathrm{ax}$ & \multirow{2}{*}{ 33.9, $\mathrm{CH}_{2}$} & $1.57^{\mathrm{d}}$ & \multirow[t]{2}{*}{34.0} & $1.58^{\mathrm{d}}$ \\
\hline $7_{\text {eq }}$ & & $1.39^{\mathrm{d}}$ & & $1.39^{\mathrm{d}}$ \\
\hline 8 & 40.9, C & - & 40.9 & - \\
\hline 9 & 48.7, $\mathrm{CH}$ & $1.64^{\mathrm{d}}$ & 48.8 & $1.64^{\mathrm{d}}$ \\
\hline 10 & $37.4, \mathrm{C}$ & - & 37.5 & - \\
\hline 11 & $24.9, \mathrm{CH}_{2}$ & $1.94^{\mathrm{d}}(2 \mathrm{H})$ & 24.9 & $1.94^{\mathrm{d}}(2 \mathrm{H})$ \\
\hline 12 & $125.8, \mathrm{CH}$ & $5.38 \mathrm{t}(3.4)$ & 125.8 & $5.38 \mathrm{t}(3.2)$ \\
\hline 13 & 142.2, C & - & 142.2 & - \\
\hline 14 & $42.9, \mathrm{C}$ & - & 42.9 & - \\
\hline \multirow[t]{2}{*}{15} & \multirow[t]{2}{*}{ 26.1, $\mathrm{CH}_{2}$} & $1.13^{\mathrm{d}}$ & \multirow[t]{2}{*}{26.1} & $1.13^{\mathrm{d}}$ \\
\hline & & $1.80^{\mathrm{d}}$ & & $1.80^{\mathrm{d}}$ \\
\hline \multirow[t]{2}{*}{16} & \multirow[t]{2}{*}{$28.3, \mathrm{CH}_{2}$} & $1.16^{\mathrm{d}}$ & \multirow[t]{2}{*}{28.2} & $1.16^{\mathrm{d}}$ \\
\hline & & $2.15^{d}$ & & $2.15 \mathrm{~m}$ \\
\hline 17 & 49.2, C & - & 49.2 & - \\
\hline 18 & $48.0, \mathrm{CH}$ & $2.41 \mathrm{dd}(13.9,4.0)$ & 47.9 & $2.41 \mathrm{dd}(13.8,3.9)$ \\
\hline $19_{\mathrm{ax}}$ & \multirow[t]{2}{*}{$42.2, \mathrm{CH}_{2}$} & 2.57 dd $(13.8,13.8)$ & \multirow[t]{2}{*}{42.1} & 2.58 dd $(13.8,13.8)$ \\
\hline $19_{\mathrm{eq}}$ & & $1.63^{\mathrm{d}}$ & & $1.62^{\mathrm{d}}$ \\
\hline 20 & $45.4, \mathrm{C}$ & - & 45.1 & - \\
\hline $21 \alpha$ & \multirow[t]{2}{*}{$46.9, \mathrm{CH}_{2}$} & $3.02 \mathrm{~d}(14.6)$ & \multirow[t]{2}{*}{46.7} & $3.01 \mathrm{~d}(14.6)$ \\
\hline $21 \beta$ & & $2.23 \mathrm{dd}(14.6,2.2)$ & & $2.23 \mathrm{dd}(14.6,2.1)$ \\
\hline 22 & 218.5, C & - & 217.6 & - \\
\hline 23 & $23.4, \mathrm{CH}_{3}$ & $1.26 \mathrm{~s}$ & 23.0 & $1.24 \mathrm{~s}$ \\
\hline \multirow[t]{2}{*}{24} & \multirow[t]{2}{*}{$64.3, \mathrm{CH}_{2}$} & $3.21 \mathrm{~d}(11.5)$ & \multirow[t]{2}{*}{64.3} & $3.25 \mathrm{~d}(11.5)$ \\
\hline & & $4.14 \mathrm{~d}(11.5)$ & & $4.12 \mathrm{~d}(11.5)$ \\
\hline 25 & $16.3, \mathrm{CH}_{3}$ & $0.90 \mathrm{~s}$ & 16.2 & $0.91 \mathrm{~s}$ \\
\hline 26 & $17.3, \mathrm{CH}_{3}$ & $0.98 \mathrm{~s}$ & 17.3 & $0.98 \mathrm{~s}$ \\
\hline 27 & $25.8, \mathrm{CH}_{3}$ & $1.26 \mathrm{~s}$ & 25.8 & $1.26 \mathrm{~s}$ \\
\hline 28 & $21.0, \mathrm{CH}_{3}$ & $0.99 \mathrm{~s}$ & 21.0 & $1.00 \mathrm{~s}$ \\
\hline 29 & $180.4, C$ & - & 179.7 & - \\
\hline 30 & 21.6, $\mathrm{CH}_{3}$ & $1.13 \mathrm{~s}$ & 21.5 & $1.14 \mathrm{~s}$ \\
\hline
\end{tabular}

a The assignments were confirmed by DQF-COSY, 2D-TOCSY, HSQC, HSQC-TOCSY and HMBC experiments.

${ }^{b}$ Acquired in methanol- $\mathrm{d}_{4} / \mathrm{D}_{2} \mathrm{O}(95: 5)$.

c Acquired in methanol- $\mathrm{d}_{4}$.

d Overlapped with other signals.

21.6, 23.4 and 25.8 respectively. One olefinic proton at $\delta 5.38(\mathrm{H}-12$, $\mathrm{t}, J=3.4 \mathrm{~Hz}$ ), together with two olefinic carbons at $\delta 125.8(\mathrm{C}-12)$ and $\delta 142.2(\mathrm{C}-13)$ suggested the presence of a $\Delta^{12}$-oleanene skeleton. An oxygen-bearing methine proton signal at $\delta 3.42$ (dd, $J=11.6,4.5 \mathrm{~Hz}$ ) and its long-range correlations observed in the HMBC spectrum with the carbon resonances at $\delta 23.4$ (C-23), 44.7 (C-4) and 64.3 (C-24) suggested the occurrence of an equatorial secondary alcoholic group at C-3. The typical 24-hydroxymethyl group found among Trifolium saponins (Pérez et al., 2013b) was deduced from the ${ }^{1} \mathrm{H}$ NMR signals at $\delta 3.21(\mathrm{~d}, J=11.5 \mathrm{~Hz})$ and $\delta 4.14$ (d, $J=11.5 \mathrm{~Hz}$ ) which correlated in the HSQC spectrum with the carbon resonance signal at $\delta 64.3$, as well as from their ROESY correlations with proton signals at $\delta 0.90$ ( $\mathrm{H}-25$, methyl group) and $\delta 1.83\left(\mathrm{H}-2_{\mathrm{ax}}\right)$. The less shielded signals in the ${ }^{13} \mathrm{C}$ NMR spectrum were found at $\delta 180.4$ and 218.5 , which were assigned as being due to a carboxylic group at C-29 and a keto group at C-22, respectively (Table 1 ). Therefore, the structure of the aglycone moiety of $\mathbf{1}$ was recognized to be 3 3,24 -dihydroxyolean-12-ene-22-oxo-29-oic acid, which is known as melilotigenin and its NMR assignments were in good agreement with those previously reported (Kang and Woo, 1988; Takeshita et al., 1991; Zheng et al., 2013). Melilotigenin has previously been identified as its methyl ester artifact in Trifolium repens (Sakamoto et al., 1992), however to the best of our 
knowledge it is reported here in its natural form for the first time within the genus Trifolium.

For the sugar portion, compound $\mathbf{1}$ showed signals corresponding to three anomeric protons at $\delta 4.46,4.87$ and 5.14, and these showed correlations in the HSQC spectrum with carbons at $\delta 105.5$, 102.1 and 102.2, respectively (Table 2). Individual sugar units were identified by a combination of DQF-COSY, 1D-TOCSY and 1D-ROESY experiments. The latter two spectra were acquired from the selective excitation of each anomeric proton. In this way, the signal at $\delta 4.46$ revealed a typical spin system of a $\beta$-glucuronic acid unit. Likewise, a spin system for a $\beta$-galactopyranosyl unit was detected for the anomeric signal at $\delta 4.87$, which was confirmed by correlations with $\mathrm{H}-5_{\mathrm{Gal}}(\delta 3.50$, brt, $J=6.0 \mathrm{~Hz})$ and $\mathrm{H}-3_{\mathrm{Gal}}(\delta 3.55$, $\mathrm{dd}, J=9.7,4.1 \mathrm{~Hz})$ in $1 \mathrm{D}-\mathrm{ROESY}$ experiment. The 1D-TOCSY $(120 \mathrm{~ms})$ experiment on the anomeric signal at $\delta 5.14$ showed that magnetization was not properly transferred beyond $\mathrm{H}-2_{\mathrm{Rha}}$ $(\delta 3.93, \mathrm{dd}, J=1.7,3.7 \mathrm{~Hz}$ ). This finding, together with the presence of a methyl doublet at $\delta 1.28(\mathrm{~J}=6.9 \mathrm{~Hz})$, is characteristic of a rhamnopyranosyl unit. A further selective TOCSY experiment on this methyl doublet $\left(H-6_{\text {Rha }}\right)$ allowed a sequential assignment of the signals from $\mathrm{H}-6_{\mathrm{Rha}}$ to $\mathrm{H}-2_{\mathrm{Rha}}$ and the presence of a rhamnopyranosyl unit was confirmed. The correlations observed in the $1 \mathrm{D}-\mathrm{ROESY}$ spectrum between $\mathrm{H}-1_{\mathrm{Rha}}$ and $\mathrm{H}-2_{\mathrm{Rha}}$, and the absence of correlation with $\mathrm{H}-3_{\mathrm{Rha}}$ and $\mathrm{H}-5_{\mathrm{Rha}}$ suggested the $\alpha$-anomer. Finally, the ${ }^{13} \mathrm{C}$ signal assignments for each sugar unit were made through an exhaustive analysis of the correlation in HSQC and HSQC-TOCSY spectra. The sequence in sugar chain and the connection with the aglycone were established by the interglycosidic HMBC/ROESY correlations, which were observed between $\mathrm{H}-1_{\mathrm{Rha}}(\delta 5.14)$ and $\mathrm{C}-2_{\mathrm{Gal}}(\delta 78.0) / \mathrm{H}-2_{\mathrm{Gal}}(\delta 3.65), \mathrm{H}-$ $1_{\mathrm{Gal}}(\delta 4.87)$ and $\mathrm{C}-2_{\mathrm{GlcA}}(\delta 77.3) / \mathrm{H}-2_{\mathrm{GlcA}}(\delta 3.76), \mathrm{H}-1_{\mathrm{GlcA}}(\delta 4.46)$ and $\mathrm{C}-3(\delta 92.4) / \mathrm{H}-3(\delta 3.42)$ of the aglycone moiety. A D configuration for glucuronic acid and galactose units, and $\mathrm{L}$ for

Table 2

${ }^{13} \mathrm{C}$ and ${ }^{1} \mathrm{H}$ NMR data for the sugar units of compounds 1 and $2(500 \mathrm{MHz}) .{ }^{\mathrm{a}}$

\begin{tabular}{|c|c|c|c|c|}
\hline & \multicolumn{2}{|l|}{$\mathbf{1}^{\mathrm{b}}$} & \multicolumn{2}{|l|}{$\mathbf{2}^{\mathrm{c}}$} \\
\hline & $\delta_{\mathrm{C}}$ & $\delta_{\mathrm{H}}(J$ in $\mathrm{Hz})$ & $\delta_{\mathrm{C}}$ & $\delta_{\mathrm{H}}(J$ in $\mathrm{Hz})$ \\
\hline & $\beta$-D-GlcA & & $\beta$-D-GlcA & \\
\hline 1 & 105.5 & $4.46 \mathrm{~d}(7.9)$ & 105.1 & $4.53 \mathrm{~d}(7.5)$ \\
\hline 2 & 77.3 & 3.76 dd $(7.9,9.4)$ & 80.4 & $3.64^{\mathrm{d}}$ \\
\hline 3 & 78.3 & 3.61 dd $(9.4,8.3)$ & 78.1 & $3.63^{d}$ \\
\hline 4 & 74.0 & 3.45 dd $(8.3,9.8)$ & 73.0 & $3.54^{\mathrm{d}}$ \\
\hline 5 & 77.0 & $3.60 \mathrm{~d}(9.8)$ & 76.6 & $3.78 \mathrm{~d}(9.2)$ \\
\hline \multirow[t]{2}{*}{6} & 175.9 & - & 173.0 & - \\
\hline & $\beta-D-G a l$ & & $\beta-\mathrm{D}-\mathrm{Gal}$ & \\
\hline 1 & 102.1 & $4.87 \mathrm{~d}(7.5)$ & 104.7 & $4.71 \mathrm{~d}(7.6)$ \\
\hline 2 & 78.0 & 3.65 dd $(7.5,9.7)$ & 73.4 & 3.55 dd $(7.6,9.9)$ \\
\hline 3 & 76.3 & 3.55 dd $(9.7,4.1)$ & 75.2 & $3.44 \mathrm{dd}(9.9,4.1)$ \\
\hline 4 & 71.5 & $3.72 \mathrm{brs}$ & 71.2 & 3.77 brs \\
\hline 5 & 76.4 & 3.50 brt (6.0) & 77.0 & 3.52 brt (6.0) \\
\hline \multirow[t]{3}{*}{6} & 62.2 & $3.69^{d}$ & 62.8 & 3.69 dd $(11.8,6.0)$ \\
\hline & & $3.77^{\mathrm{d}}$ & & $3.80^{\mathrm{d}}$ \\
\hline & $\alpha$-L-Rha & & & \\
\hline 1 & 102.2 & $5.14 \mathrm{~d}(1.7)$ & & \\
\hline 2 & 72.2 & 3.93 dd $(1.7,3.7)$ & & \\
\hline 3 & 72.1 & 3.73 dd $(3.7,9.4)$ & & \\
\hline 4 & 74.2 & 3.40 dd $(9.4,9.4)$ & & \\
\hline 5 & 69.6 & $4.11 \mathrm{dq}(9.4,6.9)$ & & \\
\hline 6 & 18.3 & $1.28 \mathrm{~d}(6.9)$ & & \\
\hline
\end{tabular}

a The assignments were confirmed by DQF-COSY, 1D-TOCSY, 1D-ROESY, HSQC, HSQC-TOCSY and HMBC experiments.

b Acquired in methanol- $\mathrm{d}_{4} / \mathrm{D}_{2} \mathrm{O}$ (95:5).

c Acquired in methanol- $\mathrm{d}_{4}$.

d Overlapped with other signals. the rhamnose unit were established after acid hydrolysis of $\mathbf{1}$, followed by derivatization of sugars and UPLC-UV-SRM/MS analysis (Tanaka et al., 2007; Pérez et al., 2014). Based on the evidence outlined above, the structure of 1 was elucidated as 3-O[ $\alpha$-L-rhamnopyranosyl-( $1 \rightarrow 2)-\beta$-D-galactopyranosyl- $(1 \rightarrow 2)-\beta$-Dglucuronopyranosyl] melilotigenin, which has not been reported previously, representing a new natural compound.

The molecular formula of compound $\mathbf{2}$ was established as $\mathrm{C}_{42} \mathrm{H}_{64} \mathrm{O}_{16}$ by HRESI-TOFMS $\left(\mathrm{m} / \mathrm{z} 823.4122[\mathrm{M}-\mathrm{H}]^{-}\right.$, calcd. for $\left.\mathrm{C}_{42} \mathrm{H}_{63} \mathrm{O}_{16}, 823.4116\right)$. Its ESI-MS showed a deprotonated molecule $[\mathrm{M}-\mathrm{H}]^{-}$at $\mathrm{m} / \mathrm{z} 823$ and the MS/MS fragmentation of this ion showed product ions formed by the neutral losses of one hexose and a hexuronic acid units, this latter following the same fragmentation pattern as shown by compound 1 . The ${ }^{1} \mathrm{H}$ and ${ }^{13} \mathrm{C}$ NMR assignments for the aglycone moieties of $\mathbf{2}$ and $\mathbf{1}$ were superimposable (Table 1 ), suggesting that melilotigenin is also the aglycone of $2 .{ }^{1} \mathrm{H}$ NMR spectrum of $\mathbf{2}$ showed signals for only two anomeric protons at $\delta 4.53$ and 4.71 (Table 2) and these were correlated in the HSQC spectrum with carbons at $\delta 105.1$ and 104.7, which were identified as $\beta$-D-glucuronic acid and $\beta$-D-galactopyranosyl units, respectively. A study of the HMBC and ROESY correlations allowed to establish the sequence in the sugar chain of compound $\mathbf{2}$ as being the same as in $\mathbf{1}$, but without the terminal rhamnopyranosyl unit. Consequently, the structure of compound 2 was elucidated as 3-O-[ $\beta$-D-galactopyranosyl- $(1 \rightarrow 2)-\beta$-D-glucuronopyranosyl] melilotigenin, which has not been reported previously, representing a new natural compound.

\subsection{Phytotoxic activity}

Phytotoxicity of the isolated compounds were tested at concentrations of $333,100,33,10,3.3$ and $1 \mu \mathrm{M}$, using $L$. sativa (lettuce), L. esculentum (tomato), L. sativum (cress) and A. cepa (onion) as STS (Macías et al., 2000). The germination and shoot developed of STS were in general not affected, while inhibitory effects on the root growth were observed (Fig. 2). However, such inhibition over L. sativum and A. cepa were much lower than those of Logran ${ }^{\circledR}$ (positive control), where a dose-dependent response were not observed and consequently $\mathrm{IC}_{50}$ values could not be determined. Similar results were observed on the other two STS (L. sativa and $L$. esculentum), except for compound 1 (Fig. 2). It showed the most significant activity with $\mathrm{IC}_{50}=254.1 \mu \mathrm{M}$ on lettuce, lower than that of $\operatorname{Logran}^{\circledR}(492.6 \mu \mathrm{M})$. The roots of tomato, however, were less affected by compound $\mathbf{1}\left(\mathrm{IC}_{50}=268.0\right.$ $\mu \mathrm{M})$ than by Logran ${ }^{\mathbb{R}}\left(\mathrm{IC}_{50}=42.1 \mu \mathrm{M}\right)$. This may be due to different sensitivities of both STS. Taking into account this and the common features between the chemical structures of $\mathbf{1}$ and the rest of tested compounds, the structure-activity relationship is discussed. Soyasaponin-I (4) has the same sugar chain as compound 1, but their aglycones are slightly different. However, compound $\mathbf{4}$ showed weaker inhibitory profile (Fig. 2), which highlights that the lack of a carboxylic group at C-29 or the hydrogenation of the carbonyl group at C-22 of the aglycone moiety cause a detrimental effect over the phytotoxicity of $\mathbf{4}$. It seems that these functional groups in the aglycone moiety are not sufficient to cause phytotoxicity in saponins, but the sugar part appears to be important as well. Compounds $\mathbf{2}$ and $\mathbf{3}$ possess the same aglycone moiety as $\mathbf{1}$, but their glycosidic portions consist of two sugar units and one sugar unit, respectively. The weaker inhibition profiles of compounds $\mathbf{2}$ and $\mathbf{3}$ compared to $\mathbf{1}$ (Fig. 2), clearly indicate that longer glycosidic chain linked at C-3 position enhance the activity. These results indicate that phytotoxicity of triterpenoid saponins may be substantially heightened by small changes in their structures (aglycone or glycosidic chain), which could make them potential allelopathic agents. 

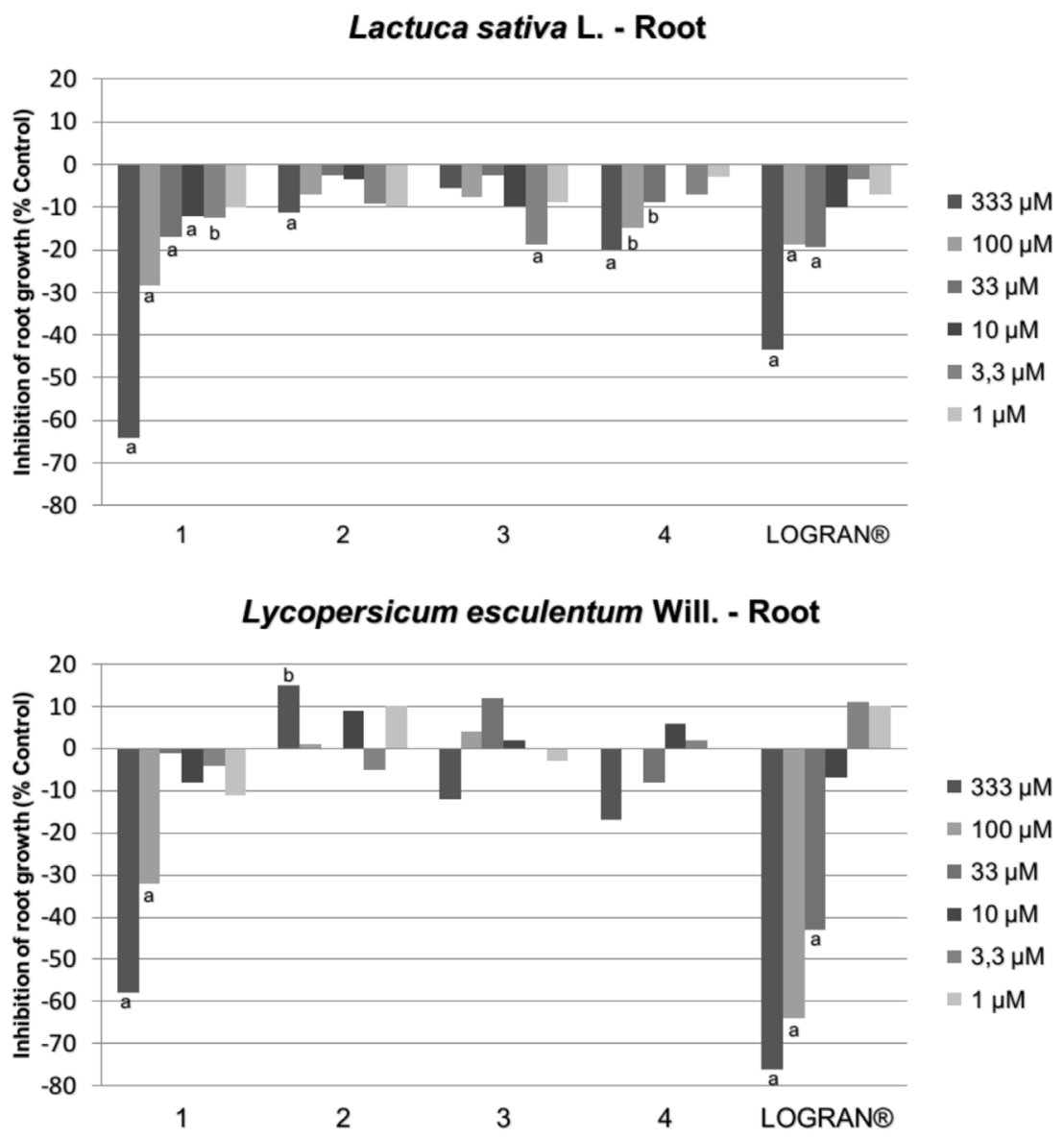

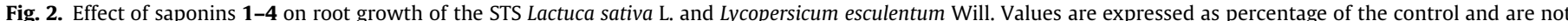

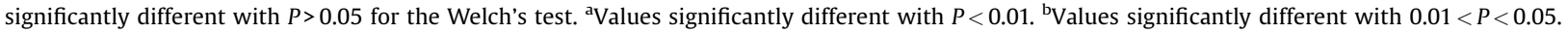

\section{Material and methods}

\subsection{General experimental procedures}

Optical rotations were measured on a PerkinElmer 241 polarimeter $\left(589 \mathrm{~nm}, 20^{\circ} \mathrm{C}\right)$. $1 \mathrm{D}$ and $2 \mathrm{D}$ NMR spectra were recorded on a Bruker Avance III HD Ascend ${ }^{\mathrm{TM}}-500$ spectrometer equipped with $5 \mathrm{~mm}{ }^{1} \mathrm{H}\left\{{ }^{109} \mathrm{Ag}-{ }^{31} \mathrm{P}\right\}$ broadband inverse (BBI) $\mathrm{z}$ gradient probe. ${ }^{1} \mathrm{H}(500.18 \mathrm{MHz})$ and ${ }^{13} \mathrm{C}(125.77 \mathrm{MHz})$ NMR spectra were recorded in methanol- $d_{4}$ at $25^{\circ} \mathrm{C}$ and chemical shifts are given on the $\delta$ scale referenced to residual methanol, $\delta_{\mathrm{H}} 3.31$ and $\delta_{\mathrm{C}}$ 49.0. Adiabatic pulse sequences using gradients were applied and all 2D spectra, except for HMBC, were recorded in the phase-sensitive mode. Exact masses of the new saponins were measured on a UPLC-QTOF ESI (Waters Synapt G2, Manchester, UK) high resolution mass spectrometer (HRESI-TOFMS). Mass spectra were recorded in negative ion mode in the range $m / z 100-2000$, with a mass resolution of 20000 and an acceleration voltage of $0.7 \mathrm{kV}$. The fragmentation patterns of the saponins were obtained using a Thermo LCQ Advantage Max (Thermo, Waltham, MA) iontrap mass spectrometer operated in the negative electrospray mode with the following parameters: spray voltage $3.9 \mathrm{kV}$, capillary voltage $-47 \mathrm{~V}$, tube lens offset $-60 \mathrm{~V}$ and capillary temperature $240^{\circ} \mathrm{C}$. Semi-preparative HPLC was performed on a chromatographic system equipped with a Gilson 321 pump, a Gilson GX-271 liquid handler with a $2 \mathrm{~mL}$ sample loop, a Gilson Prep ELS ${ }^{\mathrm{TM}}$ II detector and a semi-preparative reversed Waters Atlantis Prep T3, $5 \mu \mathrm{m},(250 \times 10 \mathrm{~mm}$, i.d $)$ column.

\subsection{Plant material}

Seeds of authenticated material of T. argutum Sol. were provided by the Genebank department of Leibniz Institute of Plant Genetics and Crop Plant Research (IPK, Gatersleben, Germany). Seeds were planted ( $1 \mathrm{~m} \times 1 \mathrm{~m}$ plots) in an experimental field of the Institute of Soil Science and Plant Cultivation in Puławy, Poland. The plants were harvested at the beginning of flowering, lyophilized, finely powdered, and used for the subsequent extraction.

\subsection{Extraction and isolation}

The dried and finely powdered T. argutum aerial parts (leaves, stems and flowers, $50 \mathrm{~g}$ ) were defatted with $\mathrm{CHCl}_{3}$ in a Soxhlet apparatus. Defatted material was then extracted three times with $\mathrm{EtOH} / \mathrm{H}_{2} \mathrm{O}(7: 3, \mathrm{v} / \mathrm{v})$ for $48 \mathrm{~h}$ by maceration at room temperature. The solvent was removed under reduced pressure and the residue ( $7.6 \mathrm{~g}$ ) was suspended in distilled water and extracted with watersaturated $n-\mathrm{BuOH}$. After removing the solvent, $2.8 \mathrm{~g}$ of butanolic extract were applied onto a $10 \mathrm{~cm} \times 6 \mathrm{~cm}, 40-63 \mu \mathrm{m}$ LiChroprep RP-18 glass column (Merck, Darmstadt, Germany), previously conditioned with water. The column was washed first with water and then gradually eluted with increasing concentration of $\mathrm{Me}_{2} \mathrm{CO}$ in $\mathrm{H}_{2} \mathrm{O}(20,40,60$ and $80 \%$, each $250 \mathrm{~mL})$ to give four fractions. Saponins were eluted in Fr-2 (408.8 mg) and Fr-3 (268.8 mg). Fr-2 was applied onto a $40 \mathrm{~cm} \times 3.2 \mathrm{~cm}$ glass column (Millipore Corp., Bedford, MA) packed with Sephadex LH-20 (Sigma-Aldrich, 
Steinheim, Germany) and performed with isocratic $\mathrm{MeOH} / \mathrm{H}_{2} \mathrm{O}$ $(8: 2, \mathrm{v} / \mathrm{v})$ at a flow rate of $2 \mathrm{~mL} / \mathrm{min}$. Ten milliliter fractions were collected and checked by TLC on Si $60 \mathrm{~F}_{254}$ silicagel (Merck, Darmstadt, Germany), developed with EtOAc/HOAc/ $\mathrm{H}_{2} \mathrm{O}$ (7:2:2). Plates were sprayed with Liebermann-Burchard reagent and heated at $130^{\circ} \mathrm{C}$. Fractions with similar profiles were combined to give two further fractions, of which Fr-2-1 contained two major saponins. This fraction was subjected to semi-preparative HPLC using a linear gradient from $25 \%$ to $50 \%$ of solvent B (MeCN containing $\left.0.2 \% \mathrm{HCO}_{2} \mathrm{H}\right)$ in solvent $\mathrm{A}\left(\mathrm{H}_{2} \mathrm{O}\right.$ containing $\left.0.2 \% \mathrm{HCO}_{2} \mathrm{H}\right)$ mobile phase with a flow of $3 \mathrm{~mL} / \mathrm{min}$ and $35^{\circ} \mathrm{C}$, yielding compounds 1 ( $7.8 \mathrm{mg}$ ) and 2 (5.1 mg) (Fig. 1). Fractionation of Fr-3 on Sephadex LH-20 and semi-preparative HPLC under the same conditions as described above, gave compounds $\mathbf{3}$ (3.7 mg) (Zheng et al., 2013) and 4 (10.2 mg) (Kitagawa et al., 1988) (Fig. 1).

3.4. 3-O-[ $\alpha$-L-rhamnopyranosyl-( $1 \rightarrow 2)$ - $\beta$-D-galactopyranosyl$(1 \rightarrow 2)-\beta$-D-glucuronopyranosyl] melilotigenin (1)

$[\alpha]_{\mathrm{D}}^{20}-22.4(\mathrm{MeOH}, \quad c \quad 0.1)$. HRESI-TOFMS, $m / z 969.4696$ $[\mathrm{M}-\mathrm{H}]^{-}$(calcd. for $\mathrm{C}_{48} \mathrm{H}_{73} \mathrm{O}_{20}$, 969.4695). ESI-MS (negative ion mode), $m / z$ (relative intensity) $969(100 \%)[\mathrm{M}-\mathrm{H}]^{-}$, which was fragmented in the MS/MS to give $m / z 951(14 \%)[\mathrm{M}-\mathrm{H}-18]^{-}, 907$ (100\%) $[\mathrm{M}-\mathrm{H}-18-44]^{-}, 823$ (2\%) $[\mathrm{M}-\mathrm{H}-146]^{-}, \quad 761$ (7\%) $[\mathrm{M}-\mathrm{H}-18-44-146]^{-}, 643$ (33\%) $[\mathrm{M}-\mathrm{H}-146-180]^{-}, \quad 599$ (5\%) $[\mathrm{M}-\mathrm{H}-18-44-146-162]^{-}, 485$ (3\%) $[\mathrm{M}-\mathrm{H}-18-44$ $-146-162-114]^{-}, 467(6 \%)[\mathrm{M}-\mathrm{H}-146-180-176]^{-}$. For ${ }^{1} \mathrm{H}$ and ${ }^{13} \mathrm{C}$ NMR data see Tables 1 and 2.

\subsection{3-O-[ $\beta$-D-galactopyranosyl-( $1 \rightarrow 2)-\beta$-D-glucuronopyranosyl] melilotigenin (2)}

$[\alpha]_{\mathrm{D}}^{20}-17.3(\mathrm{MeOH}, \quad c \quad 0.1)$. HRESI-TOFMS, $m / z 823.4122$ $[\mathrm{M}-\mathrm{H}]^{-}$(calcd. for $\mathrm{C}_{42} \mathrm{H}_{63} \mathrm{O}_{16}, 823.4116$ ). ESI-MS (negative ion mode), $m / z$ (relative intensity) $823(100 \%)[\mathrm{M}-\mathrm{H}]^{-}$, which was fragmented in the MS/MS to give $m / z 779(20 \%)[\mathrm{M}-\mathrm{H}-44]^{-}, 761$ (58\%) $[\mathrm{M}-\mathrm{H}-44-18]^{-}, 643$ (100\%) $[\mathrm{M}-\mathrm{H}-180]^{-}, 599$ (16\%) $[\mathrm{M}-\mathrm{H}-18-44-162]^{-}, 485$ (18\%) $[\mathrm{M}-\mathrm{H}-18-44-162-114]$ ,$- 467(6 \%)[\mathrm{M}-\mathrm{H}-180-176]-$. For ${ }^{1} \mathrm{H}$ and ${ }^{13} \mathrm{C}$ NMR data see Tables 1 and 2

\subsection{Acid hydrolysis}

Compounds 1 and 2 ( $1 \mathrm{mg}$ each) were treated with $2 \mathrm{M} \mathrm{HCl}$ in 1,4-dioxane/water $(1: 1, \mathrm{v} / \mathrm{v}, 2 \mathrm{~mL})$ at $80^{\circ} \mathrm{C}$ for $3 \mathrm{~h}$. After cooling, the solvent was removed with a stream of $\mathrm{N}_{2}$. The dry residue was suspended in water and aglycones were extracted with ethyl acetate $(3 \times 2 \mathrm{~mL})$. The aqueous layer containing sugars was neutralized with Amberlite IRA-400 $\left(\mathrm{OH}^{-}\right.$form $)$, dried under $\mathrm{N}_{2}$ and stored prior to analysis.

\subsection{Determination of absolute configuration of monosaccharides}

The absolute configurations of monosaccharide constituents of compounds $\mathbf{1}$ and $\mathbf{2}$ were determined according to the method reported by Tanaka et al. (2007) with the modifications described previously by us (Pérez et al., 2014). The derivatives of D-glucuronic acid, D-galactose and L-rhamnose in compound $\mathbf{1}$ and D-glucuronic acid and D-galactose in compound $\mathbf{2}$ were identified by comparison of their retention times (Rt) with those of authentic sugars (SigmaAldrich, Steinheim, Germany) treated in the same way as samples (Rt: D-glucuronic acid $10.26 \mathrm{~min}$, L-glucuronic acid $10.14 \mathrm{~min}$, Dgalactose $9.94 \mathrm{~min}$, L-galactose $10.03 \mathrm{~min}$, L-rhamnose $11.39 \mathrm{~min}$, Drhamnose $9.80 \mathrm{~min}$ ).

\subsection{Phytotoxicity bioassay}

Phytotoxicity bioassay with the monocot Allium cepa L. (onion) and dicots Lycopersicum esculentum Will. (tomato), Lepidium sativum L. (cress) and Lactuca sativa L. (lettuce) as Standard Target Species (STS) was conducted under the conditions reported in our previous work (Pérez et al., 2013a). The compounds were assayed at concentrations of $333,100,33,10,3.3$ and $1 \mu \mathrm{M}$. Control samples (buffered aqueous solutions without any test compound) and the commercial herbicide Logran ${ }^{\circledR}$, a combination of $\mathrm{N}$-(1,1-dimethylethyl)- $N$ '-ethyl-6-(methylthio)-1,3,5-triazine-2,4-diamine (Terbutryn, $59.4 \%)$ and 2-(2-chloroethoxy)- $N-\{[(4-$ methoxy-6methyl-1,3,5-triazin-2yl) amino]carbonyl\}benzene-sulfonamide (Triasulfuron, 0.6\%), were used as internal references (Macías et al., 2000) and were tested under the same conditions as samples. The evaluated parameters (germination rate, root length and shoot length) were recorded using a Fitomed ${ }^{\circledR}$ system (Castellano et al., 2001), which allowed automatic data acquisition and statistical analysis using its associated software. Data were analyzed statistically using Welch's test, with significance fixed at 0.01 and 0.05 . Results are presented as percentage differences from the control. Zero represents control, positive values represent stimulation, and negative values represent inhibition. The concentration that resulted in a $50 \%$ inhibition ( $\mathrm{IC}_{50}$ values) was calculated from the dose-response curve.

\section{Acknowledgments}

This work was supported by the seventh Framework Programs of European Community, PROFICIENCY (Contract No. 245751) and OSCAR (Contract No. FP7-KBBE-2011-5-289277).

\section{Appendix A. Supplementary data}

NMR (1H, 13C, HSQC, HMBC, ROESY, DQF-COSY, HSQC-TOCSY, selective TOCSY and ROESY), HRESI-TOFMS and ESI-MS/MS spectra for the new compounds ( 1 and 2 ). Supplementary data associated with this article can be found, in the online version, at http://dx. doi.org/10.1016/j.phytol.2015.05.020.

\section{References}

Bisby, F.A., Buckingham, J., Harborne, J.B., 1994. Phytochemical Dictionary of Leguminosae, first ed. Chapman and Hall, Cambridge.

Castellano, D., Macías, F.A., Castellano, M., Cambronero, R., 2001. Sistema automatizado para la adquisición simultánea y gestión informatizada de medidas de longitud variables. Spanish patent No. P9901565.

Ellison, N.W., Liston, A., Steiner, J.J., Williams, W.M., Taylor, N.L., 2006. Molecular phylogenetics of the clover genus (Trifolium-Leguminosae). Mol. Phylogenet. Evol. 39, 688-705.

Gülcemal, D., Masullo, M., Napolitano, A., Karayıldırım, T., Bedir, E., AlankusCalıskan, Ö., Piacente, S., 2013. Oleanane glycosides from Astragalus tauricolus: isolation and structural elucidation based on a preliminary liquid chromatographyelectrospray ionization tandem mass spectrometry profiling. Phytochemistry 86, 184-194.

Hernández, B., González, Orozco, A., Ramírez, M.V., Andrés, M.F., Joseph, P., 2011. Bioactive saponins from Microsechium helleri and Sicyos bulbosus. Phytochemistry 72, 743-751.

Jurzysta, M., Price, K., Ridout, C., Fenwick, R., 1989. The structures of four triterpenoid saponins isolated from the seed of Trifolium incarnatum. Acta Soc. Bot. Pol. 58, 575-582.

Kang, S.S., Woo, W.S., 1988. Melilotigenin, a new sapogenin from Melilotus officinalis. J. Nat. Prod. 51, 335-338.

Kitagawa, I., Wang, H.K., Taniyama, T., Yoshikawa, M., 1988. Saponin and sapogenol. XLI. 1) Reinvestigation of the structures of soyasapogenols A, B and E, oleanenesapogenols from soybean. Structures of sayasaponins I, II, and III. Chem. Pharm. Bull. 36, 153-161.

Macías, F.A., Castellano, D., Molinillo, J.M.G., 2000. Search for a standard phytotoxic bioassay for allelochemicals. Selection of standard target species. J. Agric. Food Chem. 48, 2512-2521.

Marchaim, U., Werker, E., Thomas, W.D.E., 1974. Changes in the anatomy of cotton seed coats caused by Lucerne saponins. Bot. Gaz. 135, 139-146. 
Mohamed, K.M., Ohtani, K., Kasai, R., Yamasaki, K., 1995. Oleanene glycosides from seeds of Trifolium alexandrinum. Phytochemistry 40, 1237-1242.

Oleszek, W., 1993. Allelopathic potentials of alfalfa (Medicago sativa) saponins: their relation to antifungal and hemolytic activities. J. Chem. Ecol. 19, 1063-1074.

Oleszek, W., Jurzysta, M., Górski, P.M., 1992. Alfalfa saponins-the allelopathic agents. In: Rizvi, S.J.H., Rizvi, V. (Eds.), Allelopathy: Basic and Applied Aspects. Chapman \& Hall, London, pp. 151-167.

Oleszek, W., Stochmal, A., 2002. Triterpene saponins and flavonoids in the seeds of Trifolium species. Phytochemistry 61, 165-170.

Pawelec, S., Jędrejek, D., Kowalczyk, M., Pecio, Ł., Masullo, M., Piacente, S., Macías, F. A., Simonet, A.M., Oleszek, W., Stochmal, A., 2013. Triterpene saponins from the aerial parts of Trifolium medium L. var. sarosiense. J. Agric. Food Chem. 61, 97899796.

Pérez, A.J., Calle, J.M., Simonet, A.M., Guerra, J.O., Stochmal, A., Macías, F.A., 2013a. Bioactive steroidal saponins from Agave offoyana flowers. Phytochemistry 95, 298-307.

Pérez, A.J., Kowalczyk, M., Simonet, A.M., Macías, F.A., Oleszek, W., Stochmal, A. 2013b. Isolation and structural determination of triterpenoid glycosides from the aerial parts of alsike clover (Trifolium hybridum L.). J. Agric. Food Chem. 61, 2631-2637.
Pérez, A.J., Simonet, A.M., Calle, J.M., Pecio, Ł., Guerra, J.O., Stochmal, A., Macías, F.A 2014. Phytotoxic steroidal saponins from Agave offoyana leaves. Phytochemistry 105, 92-100.

Sakamoto, S., Kofuji, S., Kuroyanagi, M., Ueno, A., Sekita, S., 1992. Saponins from Trifolium repens. Phytochemistry 31, 1773-1777.

Scognamiglio, M., D'Abrosca, B., Fiumano, V., Chambery, A., Severino, V., Tsafantakis, N., Pacifico, S., Esposito, A., Fiorentino, A., 2012. Oleanane saponins from Bellis sylvestris Cyr. and evaluation of their phytotoxicity on Aegilops geniculata Roth. Phytochemistry 84, 125-134.

Simonet, A.M., Stochmal, A., Oleszek, W., Macías, F.A., 1999. Saponins and polar compounds from Trifolium resupinatum. Phytochemistry 51, 1065-1067.

Takeshita, T., Yokoyama, K., Yi, D., Kinjo, J., Nohara, T., 1991. Four new and twelve known sapogenols from Sophorae subprostratae Radix. Chem. Pharm. Bull. 39, 1908-1910.

Tanaka, T., Nakashima, T., Ueda, T., Tomii, K., Kouno, I., 2007. Facile discrimination of aldose enantiomers by reversed-phase HPLC. Chem. Pharm. Bull. 55, 899-901.

Zheng, C.J., Jin, G.L., Jiang, Y.P., Sun, P.X., Zou, J.P., Qin, L.P., 2013. Two new triterpenoid saponins from Caragana microphylla seeds. J. Nat. Med. 67, 190-195. 